\title{
Hydrophobically Tailored Carbon Dots towards Modulating Microstructure of Reverse Micelle and Amplification of Lipase Catalytic Response
}

\author{
Saheli Sarkar, Krishnendu Das and Prasanta Kumar Das* \\ Department of Biological Chemistry, Indian Association for the Cultivation of Science \\ Jadavpur, Kolkata - 700 032, India
}

\section{Supporting Information}



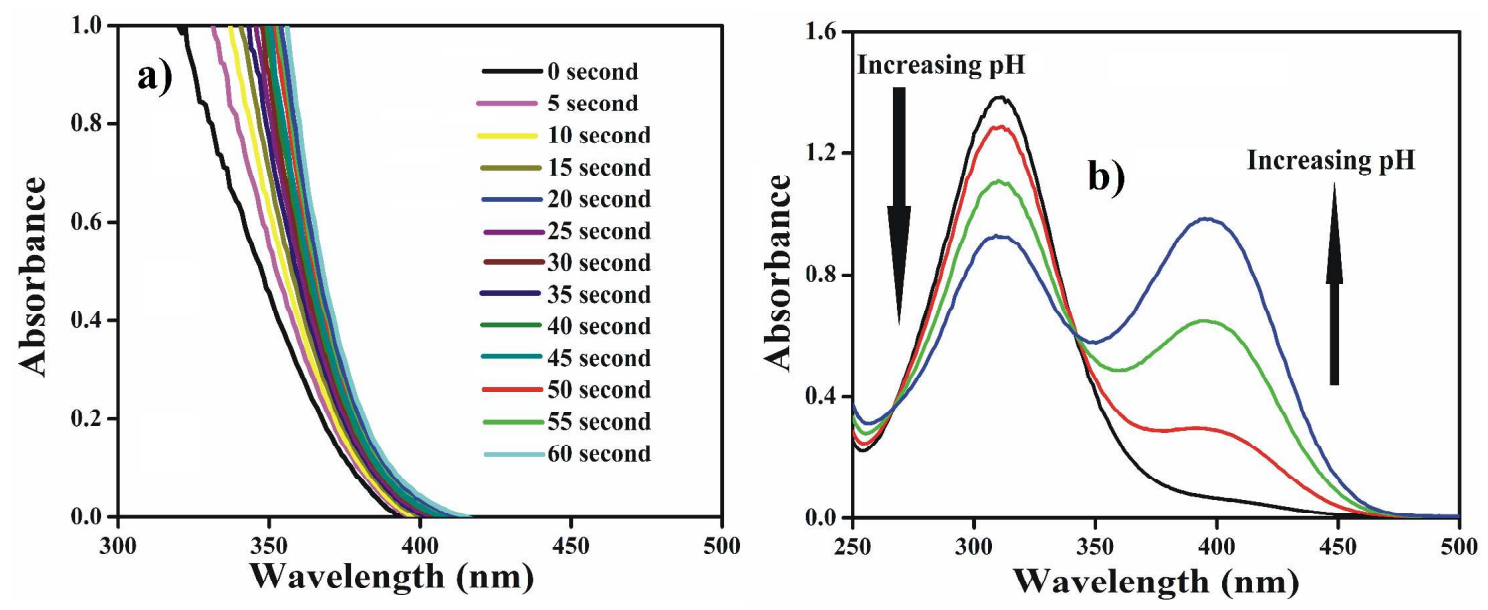

Figure S1. UV-vis spectra of a) lipase catalysed hydrolysis of $p$-nitrophenyl- $n$-octanoate at $z$ $=6.4$ and $W_{0}=44 \mathrm{CTAB}$ reverse micelle, $[\mathrm{CTAB}]=50 \mathrm{mM}$, [lipase] $=1.02 \mu \mathrm{gmL}^{-1}$, [substrate] $=3.0 \mathrm{mM}$ (spectra cannot be recorded below $300 \mathrm{~nm}$ due to off-scale noisy signal), (b) determination of isosbestic point of $p$-nitriphenol $/ p$-nitrophenolate couple with increasing $\mathrm{pH}$ within $p$-nitrophenol encapsulated CTAB reverse micelle. 

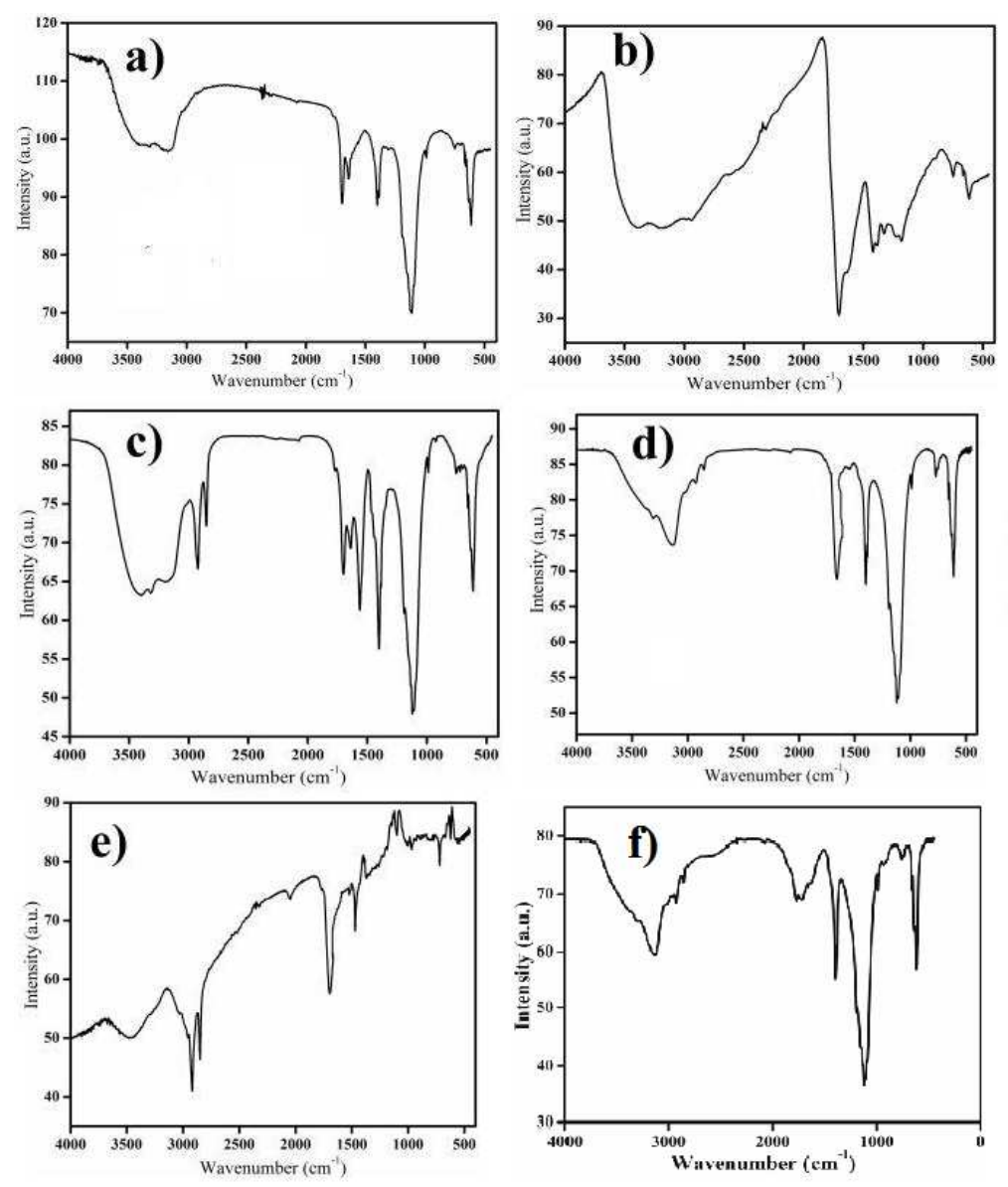

Figure S2. FTIR spectra of a) CD 1s, b) CD 1a, c) CD 2s, d) CD 2a, and e) CD 3, f) free CD derived from citric acid. 

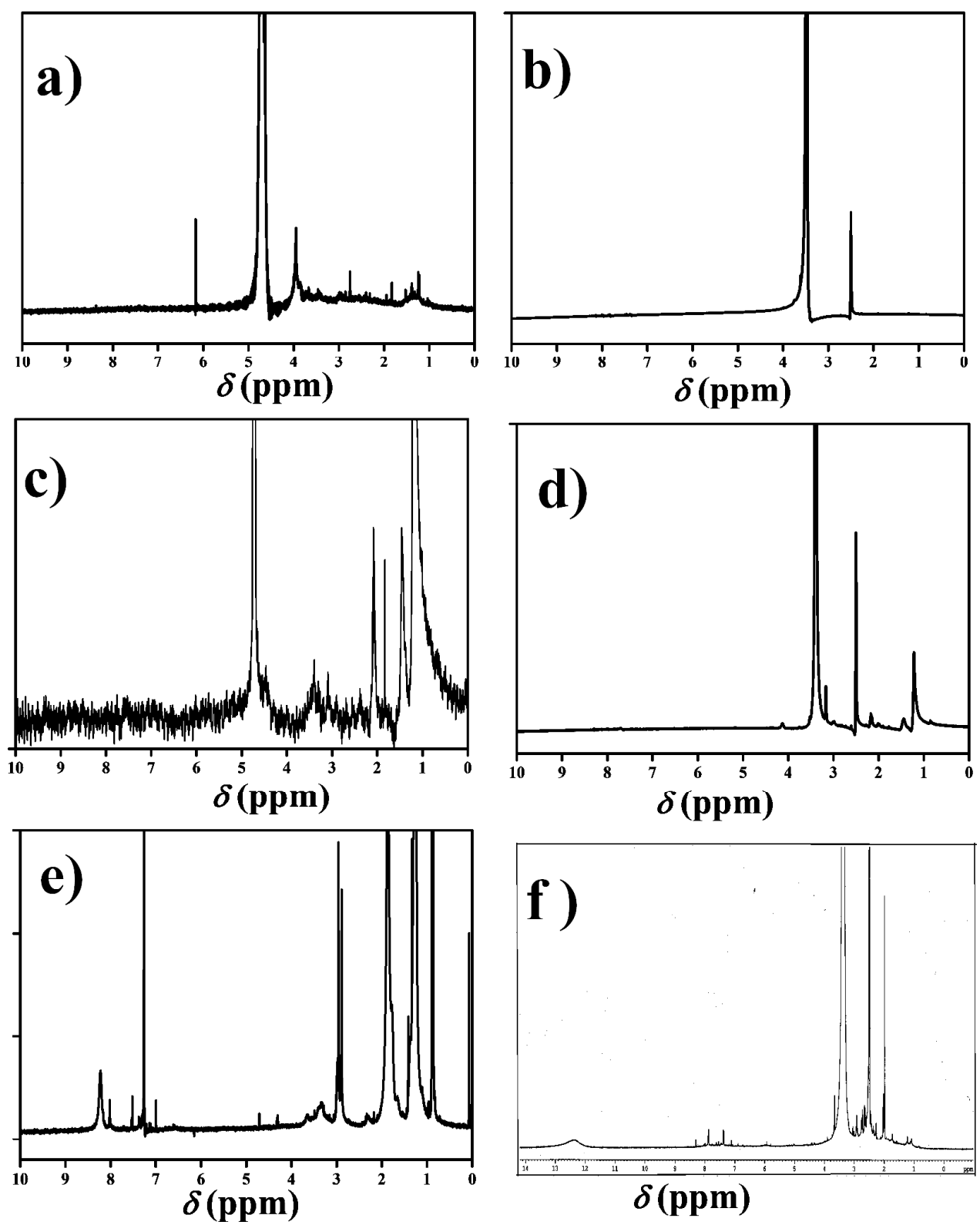

Figure S3. ${ }^{1}$ H-NMR spectra of a) CD 1s, b) CD 1a, c) CD 2s, d) CD 2a, and e) CD 3, f) free $\mathrm{CD}$ derived from citric acid. 

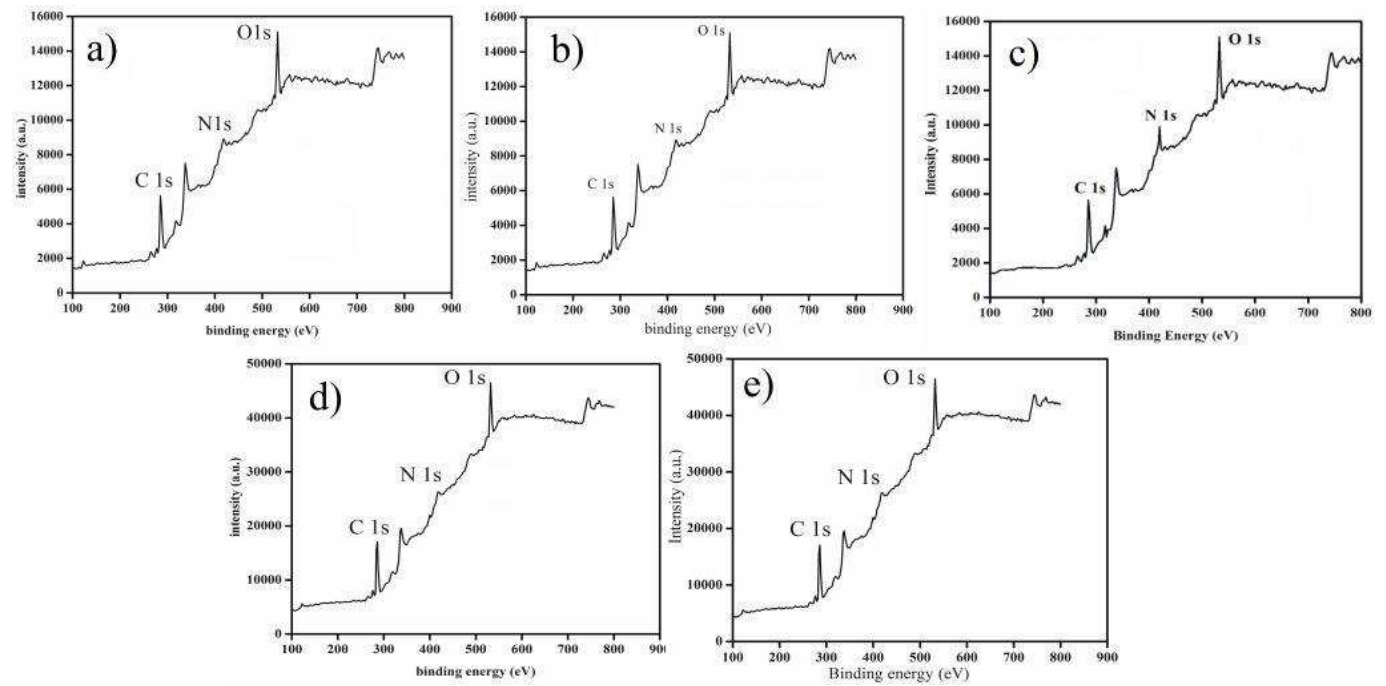

Figure S4. XPS spectra of a) CD 1s, b) CD 1a, c) CD 2s, d) CD 2a, and e) CD 3. 


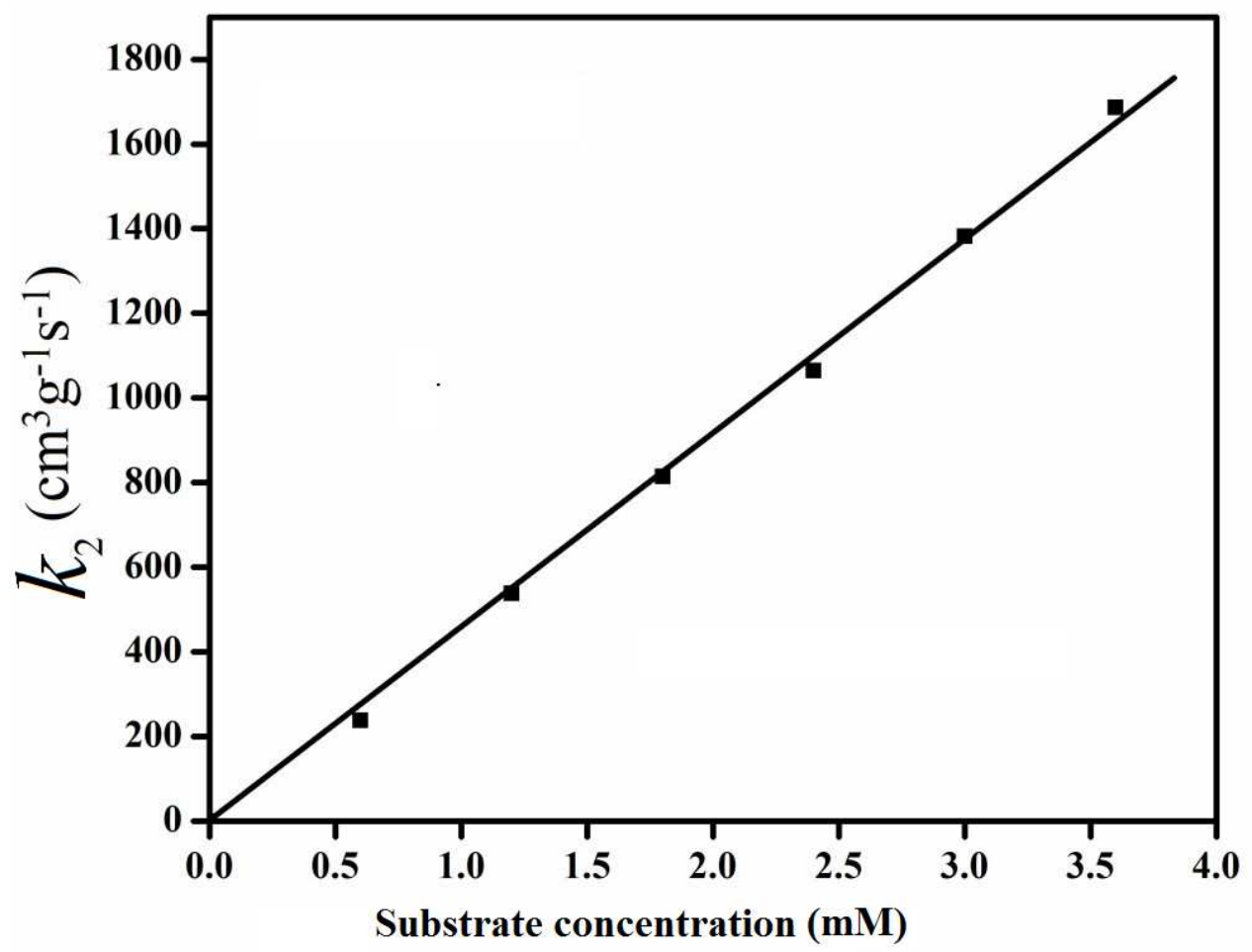

Figure S5. Plot of second order rate constant $\left(k_{2}\right)$ of lipase hydrolysis of $p$-nitrophenyl- $n$ octanoate in $\mathrm{CD} 3$-doped $\mathrm{CTAB}$-reverse micelle with varying substrate concentration at $z=$ 6.4 and $W_{0}=44$. [CTAB] $=50 \mathrm{mM}$, [lipase $]=1.02 \mu \mathrm{gmL}^{-1}$. 

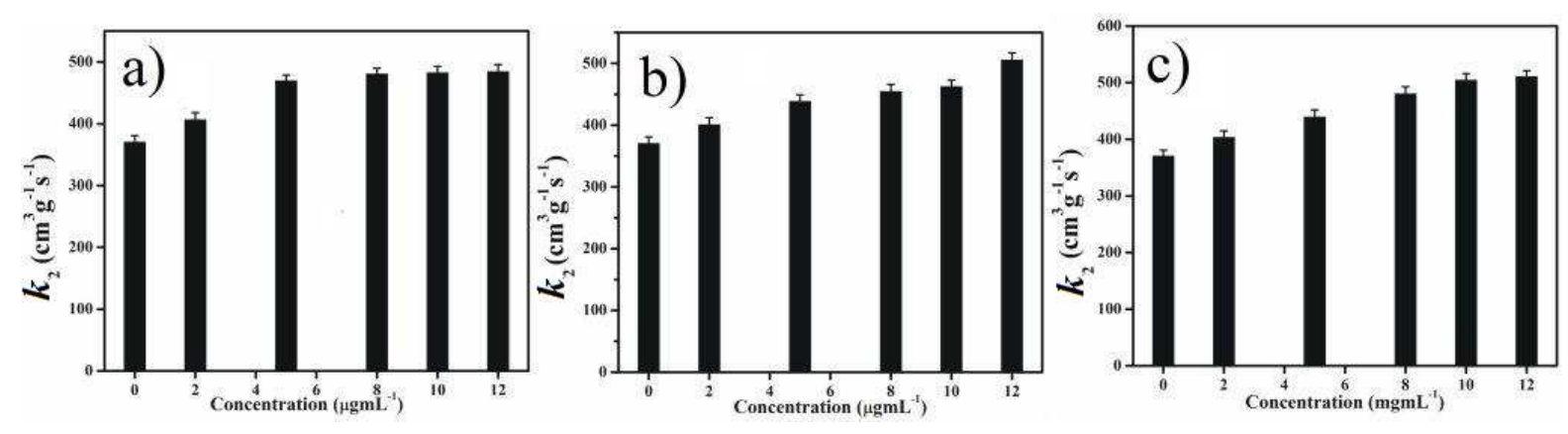

Figure S6. Variation of $k_{2}$ for lipase-catalyzed hydrolysis of $p$-nitrophenyl- $n$-octanoate in a) CD 1s, b) CD 1a and c) CD 2s doped CTAB (50 mM) reverse micelles with varying concentration of CDs at $z=6.4, W_{0}=44$. [lipase] $=1.02 \mu \mathrm{gmL}^{-1}$, [substrate] $=3 \mathrm{mM}$. Experimental errors are within $\pm 1-2 \%$. 


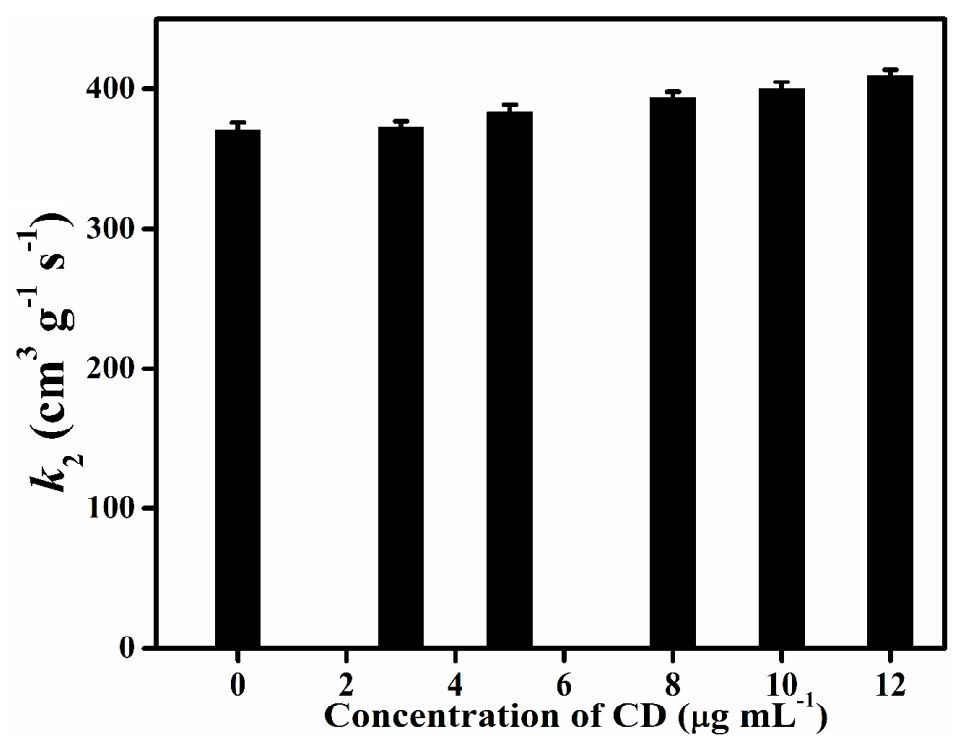

Figure S7. Variation of $k_{2}$ for lipase-catalyzed hydrolysis of $p$-nitrophenyl- $n$-octanoate in hydrophobic carbon dot (derived from citric acid only) doped CTAB $(50 \mathrm{mM})$ reverse micelles with varying concentration of CDs at $z=6.4, W_{0}=44$. [lipase] $=1.02 \mu \mathrm{gmL}^{-1}$, [substrate] $=3 \mathrm{mM}$. Experimental errors are within $\pm 1-2 \%$. 

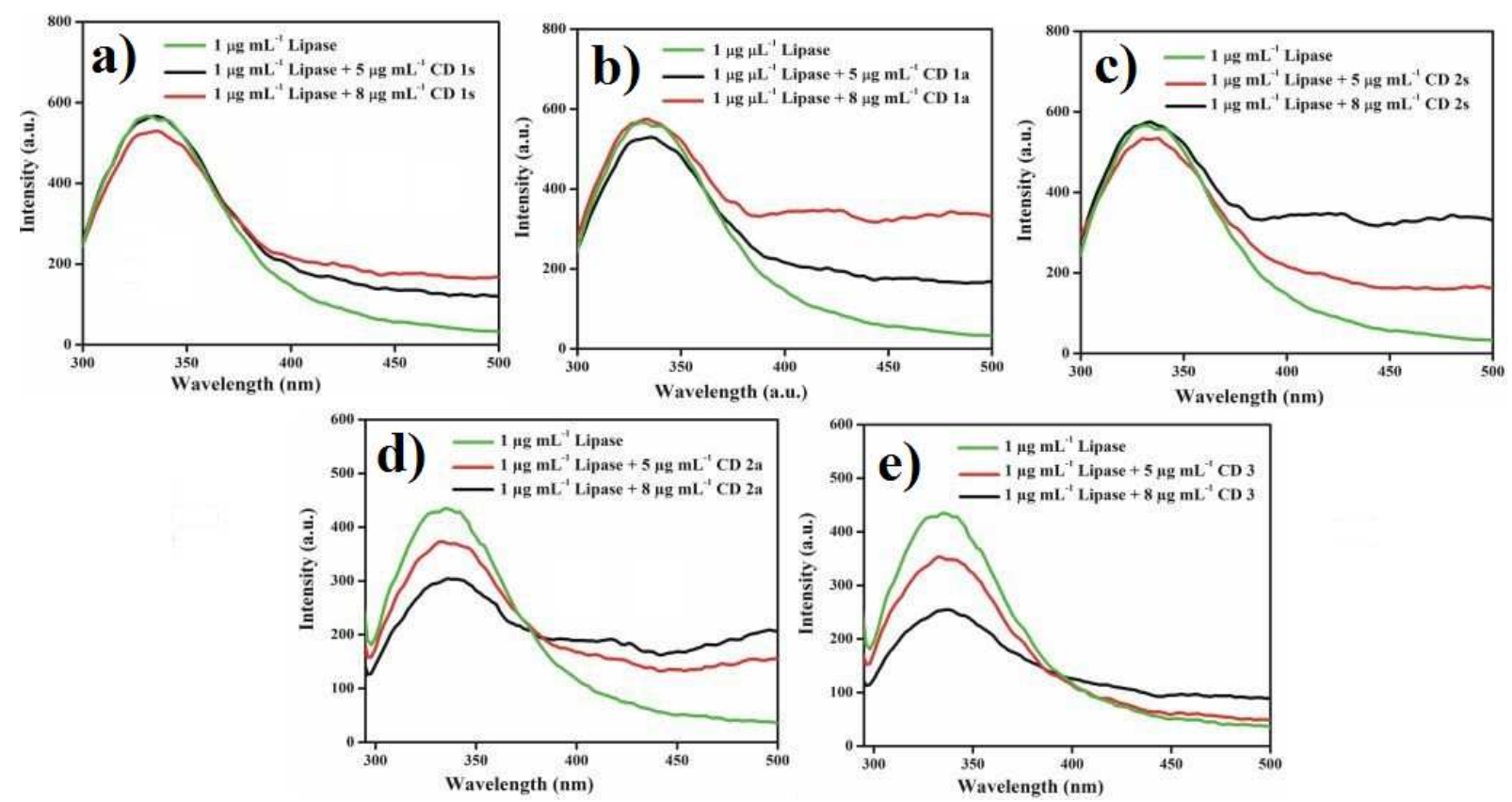

Figure S8. Fluorescence intensity of lipase in presence of different concentration of a) CD 1s, b) CD 1a, c) CD 2s, d) CD 2a, and e) CD 3. Excitation wavelength $=280 \mathrm{~nm}$. 